\title{
NILAI-NILAI PENDIDIKAN ISLAM DALAM BUDAYA SADRANAN DI DESA NGIJO KECAMATAN GUNUNGPATI KOTA SEMARANG
}

\author{
Nur Cholid dan Rois Fauzi \\ Universitas Wahid Hasyim Semarang \\ Email : nurcholid@ unwahas.ac.id
}

\begin{abstract}
Despite the development of increasingly modern era, traditional ceremonies which are a noble culture still play an important role in the society live. One of them is Nyadran culture, it has meaning for society since it contains Islamic moral values. This culture is an acculturation of Javanese-Hindu culture with Islam. Islamic education plays an important role in human life. We as Muslims should apply the Islamic values in our daily lives as a guide to reach happiness living in the world and the hereafter. Many teenagers in high school age are reluctant to carry out congregational prayers in mosques, they prefer hanging out and riding out their motorbikes, parents' advice is no longer ignored. This is a moral decline in society that appears today. This research is a qualitative-descriptive. The techniques of data collection were interviews, documentation and observation. Data analysis techniques were data reduction, data presentation, conclusion and verification. Meanwhile, to test the validity of the data, we used data triangulation and member checking techniques. The results of this study showed that the Nyadran culture is a process of sending prayers to ancestors who have passed away. This culture has been conducted by the society from generation to generation from their ancestors. The ceremony is held in Rajab, Thursday wage night Friday Kliwon. The first process that society do in this tradition is cleaning the grave, then praying together on Wednesday evening which starts at 24.00, followed by slaughtering goats on Thursday morning, after that the core of Nyadran process is praying together, recitation and distribution of food and meat goat
\end{abstract}

Keywords: The Islamic Values of Sadranan Culture

\begin{abstract}
Abstrak
Meskipun perkembangan zaman semakin modern, upacara tradisional yang merupakan budaya luhur masih memegang peranan penting bagi sebagian masyarakat dalam kehidupannya. Upacara tradisional yang memiliki makna serta nilai-nilai pendidikan Islam didalamnya salah satunya adalah budaya Nyadran. Budaya nyadran merupakan akulturasi budaya Jawa-Hindu dengan Islam. Pendidikan Islam sangat berperan penting dalam kehidupan manusia. Nilai-nilai ajaran Islam seharusnya kita terapkan dalam kehidupan sehari-
\end{abstract}


hari sebagai pedoman untuk menuju kebahagiaan dunia dan akherat. Semakin merebaknya sistem perjudian di wilayah Ngijo, anak seusia SMP sampai SMA enggan untuk melaksanakan melaksanakan sholat berjamaah di masjid, mereka lebih suka untuk nongkrong dan motor-motoran, nasehat orang tua sudah tidak dihiraukan lagi. Inilah salah satu bentuk kemerosotan akhlak di masyarakat yang muncul saat ini. Penelitian ini merupakan penelitian kualitatif-deskritif. Teknik pengumpulan data yang digunakan adalah wawancara, dokumentasi dan observasi. Teknik analisis data yang digunakan reduksi data, penyajian data, kesimpulan dan verifikasi. Untuk menguji keabsahan data menggunakan teknik triangulasi data dan member check. Hasil penelitian menunjukan bahwa budaya nyadran adalah suatu proses mengirimkan doa kepada para leluhur yang sudah meninggal dunia yang sudah berlangsung secara turun temurun dari nenek moyang. Waktu pelaksanaannya pada bulan Rajab, hari kamis wage malam Jum'at kliwon. Proses tradisi nyadran yang diawali dengan besik kubur atau membersihkan pemakaman, kemudian berdoa bersama pada hari rabu malam yang dimulai pukul 24. 00, dilanjutkan dengan pemotongan kambing pada hari kamis pagi, setelah itu inti dari nyadran yaitu doa bersama, pengajian dan pembagian makanan dan daging kambing.

\section{Kata Kunci : Nilai-Nilai Pendidikan Islam, Budaya Sadranan}

\section{A. PENDAhuluan}

Pendidikan Islam merupakan pendidikan yang berusaha mewujudkan ketundukan manusia kepada Allah dan membebaskan mereka dari penghambaan kepada sesama manusia menuju penghambaan kepada Allah semata. Islam memiliki karakter sebagai agama dakwah dan pendidikan. Dengan karakter ini, maka Islam dengan sendirinya berkewajiban mengajar, membimbing dan membentuk kepribadian umat manusia sesuai dengan nilainilai ajaran Islam. ${ }^{1}$ Ajaran-ajaran Islam harus merujuk kepada sumbersumber ajarannya, dari sumber inilah dapat menggali semua ajaran Islam secara benar dan dapat dipertanggungjawabkan kebenarannya.

Dasar penggunaan sumber ajaran Islam didasarkan pada firman Allah dalam Al-Qur'an surat An-Nisa' [4] : 59 :

\footnotetext{
${ }^{1}$ Abuddin Nata, Psikolodgi Pendidikan Islam, (Depok: RajaGrafindoPersada, 2018), hlm. 7
} 


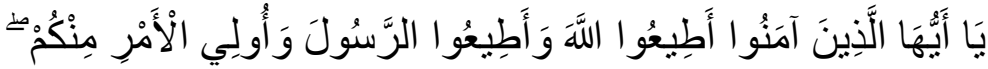

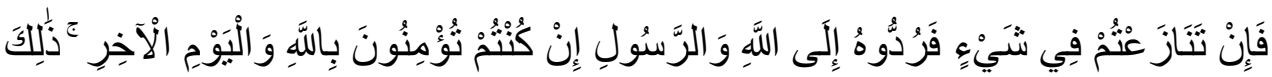

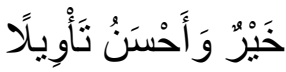

"Hai orang-orang yang beriman, taatilah Allah dan taatilah Rasul (Nya), dan ulil amri di antara kamu. Kemudian jika kamu berlainan pendapat tentang sesuatu, Maka kembalikanlah ia kepada Allah (Al Quran) dan Rasul (sunnahnya), jika kamu benar-benar beriman kepada Allah dan hari kemudian. yang demikian itu lebih utama (bagimu) dan lebih baik akibatnya." (Departemen Agama Republik Indonesia, 1991: 208). ${ }^{2}$

Umat Islam dewasa ini sedang mengalami krisis dengan berbagai bentuknya, bahkan di segala bidangnya. Dalam bidang akidah, umat Islam mulai mengalami dilema yang hebat karena sekarang semakin banyak bermunculan akidah baru yang bertolak dengan Aqidah Islam yang haq. Dalam bidang ibadah, umat Islam saat ini juga banyak yang menyepelekan soal ibadah, karena orientasinya lebih kepada hal yang bersifat duniawi daripada ukhrowi. Begitupun mengenai akhlak, dimana akhlak seseorang pada saat ini semakin merosot, jauh dari aturan Islam. Begitupun masalah perekonomian, politik, sosial budaya yang mana kian hari kian direnggut oleh perkembangan zaman yang semakin modern.

Masyarakat Ngijo adalah masyarakat yang nasionalis, humanis dan sangat toleran. Mereka dapat menerima perbedaan dalam bentuk apapun. Hidup saling menghormati, gotong royong, dan saling membantu sudah menjadi kebiasaan bagi masyarakat Ngijo. Hampir $90 \%$ penduduk Ngijo memeluk agama Islam, sehingga sebagian besar anak-anaknya juga disekolahkan ke lembaga pendidikan yang berbasis Islam. Pendidikan Islam sangat berperan penting dalam kehidupan manusia, dengan pendidikan Islam manusia dapat mengetahui mana yang baik dan buruk, mana yang halal dan haram, serta hal lain yang berkaitan dengan syariat.

\footnotetext{
2Departemen Agama RI, al-Qur'an dan Terjemah, (Jakarta, t.p, 1998), hlm. 208.
} 
Nyadran atau istilah lainnya adalah Ruwahan berasal dari kata Ruwah, sebagai penyebutan bulan Sya'ban dalam kalender hijriyah. Ruwah dimaksudkan adalah Arwah (ruh-ruh, bentuk jamak dalam bahasa Arab). Sudah menjadi tradisi bagi masyarakat Jawa khususnya, setiap bulan Ruwah menjelang Puasa, orang pergi ke pekuburan, membersihkan makam untuk memperingati dan menghormati arwah leluhurnya.

Didesa Ngijo tradisi Nyadran dilaksanakan menjelang bulan Ramadhan, di bulan Rajab pada hari kamis wage malam jum'at kliwon. Dalam budaya sadranan sebenarnya sangat penuh dengan nilai-nilai pendidikan Islam. Diantaranya adalah pendidikan untuk berbhakti kepada kedua orang tua yang sudah meninggal dunia. Mengirimkan doa dan memohonkan ampunan kepada Allah atas segala salah dan khilaf orang tua semasa hidupnya. Bersedekah kepada orang lain, saling tolong menolong, ikhlas, menjalin tali silaturahmi dan lain sebagainya.

\section{B. PEMBAHASAN}

\section{Pengertian Nilai Pendidikan Islam}

\section{a. Nilai}

Hakikat Nilai merupakan konsep abstrak dalam diri manusia mengenai apa yang baik dan apa yang buruk. Dalam buku Pendidikan Pancasila disebutkan bahwa istilah nilai dipakai untuk menunjuk kata benda abstrak yang artinya "keberhargaan" (worth) atau "kebaikan" (goodness). Nilai menunjuk kata kerja yang artinya suatu tindakan kejiwaan tertentu dalam melakukan penilaian. Nilai pada hakikatnya adalah sifat atau kualitas yang melekat pada objek. Nilai pada manusia dipakai dan diperlukan untuk menjadi landasan alasan, motivasi dalam segala sikap, tingkah laku dan perbuatannya.

Menurut Sidi Gazalba yang dikutip Chabib Thoha mengartikan nilai sebagai berikut: Nilai adalah sesuatu yang bersifat abstrak, ia 
ideal, nilai bukan benda konkrit, bukan fakta, tidak hanya persoalan benar dan salah yang menuntut pembuktian empirik, melainkan penghayatan yang dikehendaki dan tidak dikehendaki.

Sedang menurut Chabib Thoha nilai merupakan sifat yang melekat pada sesuatu (sistem kepercayaan) yang telah berhubungan dengan subjek yang memberi arti (manusia yang meyakini). Jadi Nilai adalah sesuatu yang bermanfaat dan berguna bagi manusia sebagai acuan tingkah laku. Macam-macam nilai menggolongkan sumber nilai yang berlaku dalam kehidupan manusia menjadi dua macam, yaitu :

1) Nilai Ilahi

Nilai Ilahi adalah nilai yang dititahkan Tuhan melalui para Rasul-Nya, yang berbentuk takwa, iman, adil, yang diabadikan dalam wahyu ilahi.

2) Nilai Insani

Nilai Insani adalah nilai yang tumbuh atas kesepakatan manusia serta hidup dan berkembang dari peradaban manusia. Nilai ini bersifat dinamis dan keberlakuan serta kebenarannya relative yang dapat dibatasi oleh ruang dan waktu.

\section{b. Pendidikan Islam}

Pendidikan Islam adalah suatu sistem kependidikan yang mencakup seluruh aspek kehidupan yang dibutuhkan oleh hamba Allah, sebagaimana Islam telah menjadi pedoman bagi seluruh aspek kehidupan manusia, baik duniawi maupun ukhrawi.

Dalam khazanah pemikiran pendidikan Islam, terdapat banyak istilah yang digunakan oleh ulama dalam memberikan pengertian tentang pendidikan Islam.

1) Istilah al-Tarbiyah 
Penggunaan istilah al-tarbiyah berasal dari kata rabb. Walaupun kata ini memiliki banyak arti akan tetapi pengertian dasarnya menunjukan makna tumbuh, berkembang, memelihara, merawat, mengatur, dan menjaga kelestarian atau eksistensinya. Pendidikan Islam yang dikandung dalam term "al-tarbiyah" terdiri atas empat unsur pendekatan, yaitu: (1) memelihara dan menjaga fitrah peserta didik menjelang dewasa (baligh). (2) mengembangkan seluruh potensi menuju kesempurnaan. (3) mengarahkan seluruh fitrah menuju kesempurnaan. melaksanakan pendidikan secara bertahap. ${ }^{3}$

2) Istilah al-Ta'lim

Rasyid Ridha dalam Ramayulis, mengartikan al-ta'lim sebagai proses transmisi berbagai ilmu pengetahuan pada jiwa individu tanpa adanya batasan dan ketentuan tertentu.

3) Istilah al-Ta'dib

Menurut Al-Atas, istilah yang paling tepat untuk menunjukan pendidikan Islam adalah al-ta'dib. Al-ta'dib berarti pengenalan dan pengakuan secara berangsur-angsur yang ditanamkan ke dalam diri manusia (peserta didik) tentang tempat-tempat yang tepat dari segala sesuatu di dalam tatanan penciptaan. Dengan pendekatan ini, pendidikan akan berfungsi sebagai pembimbing ke arah pengenalan dan pengakuan tempat Tuhan yang tepat dalam tatanan wujud dan kepribadiannya.

Dari pemaparan diatas dapat diambil kesimpulan bahwa pendidikan Islam adalah usaha bimbingan jasmani dan rohani pada

\footnotetext{
${ }^{3}$ Wahyudi, M. Jindar, Nalar Pendidikan Qur'ani, (Yogyakarta: Apeiron Philotes, 2006), hlm. 53
} 
tingkat kehidupan individu dan sosial untuk mengembangkan fitrah manusia berdasarkan hukum-hukum Islam dari sumber utamanya kitab suci al-Quran dan al-Hadits menuju terbentuknya manusia ideal (insan kamil) yang berkepribadian muslim dan berakhlak terpuji serta taat pada Islam sehingga dapat mencapai kebahagiaan didunia dan di akherat.

Nilai pendidikan Islam yang ada dalam kitab al qur'an diantaranya adalah:

1) Manusia oleh Allah diperintahkan untuk saling tolong menolong dan bekerjasama dengan sesamanya, Allah SWT berfirman:

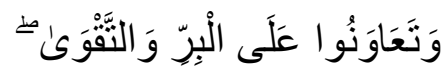

"Dan bertolong-tolonganlah kamu sekalian pada kebaikan dan taqwa (QS. Al Maidah, Ayat: 2). ${ }^{4}$

Allah SWT Manusia diperintahkan untuk saling tolongmenolong dan saling bantu-membantu antara satu dengan yang lainnya. Agar kelak dia diberi kemudahan dalam hidupnya untuk melakukan ibadah dan melaksanakan kegiatan sehari-hariannya.

2) Dalam hubungan manusia di masyarakat Allah SWT juga memerintahkan agar manusia selalu mensyukuri atas nikmatnikmat yang telah diberikan oleh Allah kepadanya dan tidak mengkufurinya, sebagaimana sebuah ayat al Qur'an yang berbunyi:

$$
\text { فَاذْكُرُونِي أَذْكُرْكُمْ وَاشْكُرُور الِي وَلَا تَكْفُرُونِ }
$$

"Maka ingatlah kepada-Ku, akupun akan ingat kepadamu. bersyukurlah kepada-Ku, dan janganlah kamu ingkar kepadaKu" (QS. Al Baqarah, Ayat: 152). ${ }^{5}$

${ }^{4}$ Departemen Agama RI, al-Qur'an dan Terjemah, hlm. 45.

${ }^{5}$ Departemen Agama RI, al-Qur'an dan Terjemah, hlm. 45. 
Demikianlah Allah SWT menegakkan syariatnya dengan penuh kenikmatan yang dijanjikannya bagi hamba yang taat dan juga ancaman akan datangnya hukuman bagi hamba yang ingkar atas nikmat tersebut.

\section{c. Ruang Lingkup Pendidikan Islam}

Ruang lingkup pendidikan Islam ada empat:

1) Pendidikan Tauhid

Tauhid adalah dasar tempat pijakan semua ajaran Islam. Tauhid merupakan hal pertama yang harus diajarkan kepada peserta didik agar mereka terhindar dari keyakinan syirik yang akan mengakibatkan diri mereka terjerumus ke dalam jurang kenistaan.

2) Pendidikan Akhlak

Pendidikan Akhlak memberikan contoh atau teladan yang baik kepada para peserta didik dalam kehidupan sehari-hari, baik dalam keluarga maupun di tengah masyarakat.

3) Pendidikan Akal

Yang dimaksud Pendidikan akal ialah menuntun dan mengembangkan daya fikir rasional dan objektif. Jika kita renungkan lebih jauh pensyariatan pendidikan akal sejak dini akan diperoleh gambaran bahwa Islam benar-benar agama rasional yang sangat cocok dengan fitrah manusia karena kehidupan mereka yang makin lama makin didasarkan pada pemikiran rasional yang objektif.

4) Pendidikan Jasmani

Pendidikan jasmani sangat penting karena sesuai dengan fitrah manusia yang terdiri atas dua unsur, yaitu rohani dan jasmani. Ibarat dua sayap burung, dia tidak dapat terbang jika salah satu sayapnya rusak atau sakit. Begitu juga dengan manusia, dia tidak akan dapat 
meraih kebaikan, kecuali jika rohani dan jasmaninya berfungsi dengan baik.

\section{Budaya Sadranan}

\section{a. Pengertian Budaya}

Kata budaya adalah bentuk jamak dari kata "budi" dan "daya" yang berarti cinta, karsa, dan rasa. Kata "budaya" sebenarnya berasal dari bahasa sansekerta, budhayah, yaitu bentuk jamak kata buddhi yang berarti budi atau akal. Dalam bahasa Inggris, kata budaya berasal dari culture. Dalam bahasa Belanda diistilahkan dengan kata cultuur. Dalam bahasa latin, berasal dari kata colera. Corela berarti mengolah, dan mengerjakan, menyuburkan, dan mengembangkan tanah (bertani). ${ }^{6}$ Kemudian pengertian ini berkembang dalam arti culture, yaitu sebagai segala daya dan aktivitas manusia untuk mengolah dan mengubah alam.

Pengertian budaya atau kebudayaan menurut beberapa ahli, sebagai berikut:

1) E.B Tylor buadaya adalah suatu keseluruhan kompleks yang meliputi pengetahuan, kepercayaan, kesenian, moral, keilmuan, hukum, adat istiadat dan kemampuan yang lain, serta kebiasaan yang di dapat oleh manusia sebagai anggota masyarakat.

2) R. Linton kebudayaan dapat dipandang sebagai konfigurasi tingkah laku yang dipelajari dan hasil tingkah laku yang dipelajari, di mana unsur pembentukannya di dukung dan diteruskan oleh anggota masyarakat lainnya.

3) Koentjaraningrat, budaya adalah keseluruhan sistem, gagasan,

${ }^{6}$ Elly Setiadi M. dkk, Ilmu Sosial Budaya Dasar, (Jakarta: Kencana Prenada Media Group, 2006), hlm. 28. 
tindakan, dan hasil kerja manusia dalam rangka kehidupan masyarakat yang dijadikan milik manusia dengan belajar. Budaya dapat diperoleh dari belajar, dan gagasan dalam pikiran dan kemudian terwujud dalam seni.

4) Selo Soemardjan dan Soelaeman Soemardi kebudayaan adalah semua hasil karya, rasa, dan cipta masyarakat.

5) Herkovits, kebudayaan adalah bagian dari lingkungan hidup yang diciptakan oleh manusia.

6) Ki Hadjar Dewantoro mengatakan bahwa kebudayaan adalah "sesuatu" yang bekembang secara kontinyu, konvergen, dan konsentrasi. Jadi kebudayaan bukanlah sesuatu yang statis, baku atau mutlak. Kebudayaan berkembang seiring dengan perkembangan evolusi batin maupun fisik manusia secara kolektif. ${ }^{7}$

Dengan demikian, kebudayaan atau budaya menyangkut keseluruhan aspek kehidupan manusia baik materiel maupun non materiel. Sebagian besar ahli yang mengartikan kebudayaan seperti ini kemungkinan besar sangat dipengaruhi oleh pandangan evolusionisme, yaitu teori yang mengatakan bahwa kebudayaan itu akan berkembang dari tahapan yang sederhana menuju tahapan yang lebih kompleks.

\section{b. Pengertian Sadranan}

Sadran, menyadran artinya mengunjungi makam atau tempat keramat pada bulan ruwah untuk memberikan doa kepada leluhur (ayah, ibu, dan sebagainya) dengan membawa bunga atau sesajian. ${ }^{8}$ Rohman (2010) yang menyebutkan nyadran sebagai proses membersihkan hati. Pengertian nyadran dalam pemahaman ini

${ }^{7}$ Setiadi, Elly M. dkk, 2006, Ilmu Sosial Budaya Dasar, hlm. 18.

${ }^{8}$ Departemen Pendidikan Nasional, Kamus Besar Bahasa Indonesia, (Jakarta:

Gramedia Pustaka Utama, 2008), hlm. 1199 
didasarkan pada asal kata nyadran "sodrun, sadran, sudra" yang berarti dada atau hati, berkumpul dengan orang awam dalam situasi sama. Purwadi (2006:12) mengartikan nyadran sebagai tradisi mengunjungi makam leluhur yang diambil dari bahasa Sansekerta "sadra".

\section{HASIL PENELITIAN}

\section{Sejarah Sadranan/Nyadran di desa Ngijo}

Kegiatan sadranan di desa Ngijo secara jelas tidak diketahui secara pasti kapan dimulainya. Masyarakat Ngijo yang ada saat ini mengetahui bahwa kegiatan ini sudah dilaksanakan sejak zaman dahulu turun temurun dari leluhur mereka.

Kyai Asy'ari atau Kyai Guru adalah seorang ulama dari Mataram. Berdasarkan wawancara dengan Mbah Sudardini, kegiatan Sadranan ini pada awalnya bukan untuk mengirim doa untuk para arwah. Menurut cerita dari para sesepuh dahulu, bahwa sekitar tahun 1942 kerajaan Mataran diserang oleh tentara Belanda, Kerajaan Mataram mengalami kekalahan, akhirnya kerajaan Mataram kocar-kacir. Tentara Hizbullah dari kerajaan Mataran pecah menjadi dua. Ada yang sebagian memihak Belanda dan ada yang memihak kerajaan. Setelah kerajaan Mataram dikuasai oleh Belanda, para pejabat kerajaan meninggalkan istana untuk menyelamatkan diri. Tidak luput Kyai Asyari, beliau bersama tentara Hizbullah yang pro dengan kerajaan Mataram, meninggalkan istana. Akhirnya sampailah Kyai Asyari di desa Ngijo. Di desa Ngijo Kyai Asy'ari bersama tentara Hizbullah beristirahat (sare). Maka sampai sekarang tempat tersebut terkenal dengan sebutan Sarean bukan makam. Karena ditempat itu tidak ada makam Kyai Asyari. Melainkan hanya tempat sare atau tempat beristirahat.

Waktu beristirahat, beliau bersama tentara Hizbullah mencari seekor kambing untuk dimakan bersama (mayoran) karena telah selamat dari 
kejaran tentara Belanda. Setelah kambing diperoleh, kemudian disembelih dan dimasak, penduduk desa yang ada disekitarnya diundang untuk makan bersama-sama. Namun sebelum makan bersama dimulai Kyai Asyari mengajarkan ajaran Islam kepada penduduk sekitar. Setelah dirasa cukup dalam mengajarkan ajaran Islam, kemudian membaca tahlil dan doa bersama. Barulah setelah selesai berdoa mereka makan bersamasama.

Tidak diketahui berapa lama beliau tinggal didesa Ngijo, akan tetapi di desa Ngijo beliau sudah banyak mengajarkan tentang ajaran Islam, sehingga masyarakat Ngijo yang dahulunya buta tentang pengetahuan agama berangsur-angsur dapat memahami dan mengerti tentang Islam. Kyai Asy'ari oleh orang-orang dahulu tidak dipanggil dengan Kyai Asy'ari, tetapi dipanggil dengan Mbah Senari. Karena dengan ilmu agama Islam yang diajarkan kepada masyarakat Ngijo dapat menyinari (menerangi) masyarakat Ngijo dengan cahaya keislaman.

\section{Peninggalan Kyai Asy'ari}

Menurut penuturan mbah Jumari, sarean kyai Asy'ari ada cantriknya (pengawal), kebo bule, cemeti dan jalu beksi (merah delima). Sedangkan Mbah Sudardini menceritakan, sebelum Kyai Asy'ari meninggalkan desa Ngijo, beliau di Ngijo meninggalkan jubah, tongkat, kopyah dan kebo landoh yang dikubur ditempat tersebut.

Kebo landoh sebenarnya bukanlah seekor kerbau, akan tetapi kebo landoh adalah secuil dari kulit kerbau bule yang di asma' dan disabdo oleh Kyai Asyari yang berubah menjadi kerbau. Ada warga bernama ibu Asih, yang sudah pernah melihat kerbau tersebut secara nyata, saat ibu Asih akan pergi ke hutan mencari rumput.

\section{Pelaksanaan Sadranan di desa Ngijo}

Kegiatan Sadranan di desa Ngijo dilaksanaka pada bulan Rajab hari 
kamis wage malam Jum'at kliwon, namun jika tidak ditemukan hari kamis wage malam jum'at kliwon maka sadranan akan dilaksanakan pada hari kamis wage malam jum'at kliwon dibulan Sya'ban. Kegiatan Sadranan dipimpin oleh bapak Sunari sebagai ketua RW 02 Kelurahan Ngijo yang dibantu oleh panitia. Dana kegiatan sadranan di desa Ngijo dana diperoleh dari iuran warga setempat.

Sebelum pelaksanaan sadranan, pada hari Minggu masyarakat melaksanakan kerja bhakti untuk membersihkan makam, membuat galian tanah untuk menyembelih kambing, membuat gantungan untuk menguliti kambing dan membuat dapur untuk memasak daging kambing tersebut.

Prosesi sadranan di desa Ngijo dimulai sejak hari rabu malam, yaitu pukul 24. 00. Warga masyarakat Ngijo dan masyarakat dari luar Ngijo melaksanakan tahlilan bersama. Dalam kegiatan tahlilan malam ini, setelah warga masyarakat berkumpul, lampu dimatikan, diesel dan apaapa yang dapat mengganggu kekhusukan dalam melaksanakan tahlilan dimatikan. Pagi harinya sesudah sholat subuh kemudian dilakukan penyembelihan kambing yang dilaksanakan di sarean tersebut dan dipimpin oleh pemuka agama (modin). Sekitar pukul 09. 00 acara Sadranan dimulai dan selesai pukul kira-kira 13. 00. Barulah warga pulang ke rumah masing-masing. Kebiasaan yang sudah berjalan, warga yang berasal dari desa lain, teman atau kerabat yang datang dari jauh dipersilahkan untuk mampir ke rumah warga Ngijo. Mereka dapat bertemu dan berkumpul untuk saling berbagi cerita dan saling bercengkerama.

4. Nilai-nilai Pendidikan Islam yang terkandung dalam budaya sadranan di desa Ngijo

a. Nilai Sejarah

Tradisi Nyadran adalah salah budaya di Indonesia yang tradisi 
warisan leluhur yang terdapat nilai-nilai pendidikan yang tersimpan demi kemaslahatan umat yang perlu dijaga.

b. Nilai Religius

Nilai religious yang terkandung dalam budaya sadranan di desa Ngijo diantaranya adalah: 1). Mengingat akan kematian, 2). Tahlilan, 3). Sedekah, 4). Ikhlas dalam segala hal, 5). Bersatu dan gotong royong, 6). Menjalin tali silaturrahmi, 7). Menghormati budaya

c. Nilai Moral

Nilai moral yang terkandung di dalam budaya nyadran yaitu supaya kita dapat menyeimbangkan antara urusan dunia dan akhirat.

\section{KESIMPULAN}

Kesimpulan dari penilitian budaya sadranan di Desa Ngijo yang telah di paparkan di atas, banyak terkandung nilai pendidikan Islam, diantaranya adalah mengingat kematian, memperbanyak doa, bersedekah, Ihkas, mengajarkan rasa kebersamaan, saling tolong-menolong dan bekerja-sama. Seperti menyumbangkan tenaga dan dana dengan sistim iuran. Menumbuhkan rasa cinta tanah air, cinta kebudayaan daerah dan melestarikannya. Hidup saling menghormati antara satu sama lain, dengan mempererat tali persaudaraan, rasa persatuan dan kesatuan.

\section{DAFTAR PUSTAKA}

Departemen Agama RI, al-Qur'an dan Terjemah, Jakarta, t.p, 1998.

Departemen Pendidikan Nasional, Kamus Besar Bahasa Indonesia, Jakarta: Gramedia Pustaka Utama, 2008.

Nata, Abuddin, Psikolodgi Pendidikan Islam, Depok: RajaGrafindoPersada, 2018.

Setiadi, Elly M. dkk, Ilmu Sosial Budaya Dasar, Jakarta: Kencana Prenada Media Group, 
Jurnal Pendidikan Agama Islam Universitas Wahid Hasyim Semarang

2006.

Wahyudi, M. Jindar, Nalar Pendidikan Qur'ani, Yogyakarta: Apeiron Philotes, 2006. 